\title{
Perceived Parental Rejection Has an Indirect Effect on Young Women's Drinking to Cope
}

\author{
Laura Rundell ${ }^{1}$, Carrie M. Brown ${ }^{2}$, Rachel E. Cook ${ }^{2}$ \\ ${ }^{1}$ Department of Psychology, Southern Illinois University, Carbondale, USA \\ ${ }^{2}$ Department of Psychology, Agnes Scott College, Decatur, USA \\ Email: laura.rundell@gmail.com
}

Received September $6^{\text {th }}, 2012$; revised October $4^{\text {th }}, 2012$; accepted November $1^{\text {st }}, 2012$

\begin{abstract}
While it has been documented that perceived parental rejection is associated with the use of alcohol, it has not been documented if perceived parental rejection is associated with drinking motives, or self-perceived reasons for drinking alcohol. Therefore, the purpose of the present study was to determine if, among young women specifically, perceived parental rejection has an indirect effect, via negative self-esteem, on the drinking motives of coping, enhancement, and sociability. Ninety-five female young adults $(M$ age $=$ 21.15) completed an online questionnaire that included measures of perceived maternal and paternal rejection, negative self-esteem, and drinking motives. The results revealed that higher levels of both perceived maternal rejection and paternal rejection had indirect effects, via more negative self-esteem, on the decision to drink alcohol as a means of coping, but not as a means of enhancement or sociability. These findings suggest that, among young women, higher levels of perceived parental rejection extend to the drinking motive of coping, specifically.
\end{abstract}

Keywords: Parental Rejection; Alcohol; Self-Esteem

\section{Introduction}

Parental Acceptance-Rejection Theory (PARTheory) is a theory that aims to predict and explain the major sources and effects of parental acceptance and rejection among people worldwide (Rohner, 1986; Rohner, Khaleque, \& Cournoyer, 2011). In PARTheory, parental acceptance-rejection refers to a bipolar dimension, with parental acceptance on one end and parental rejection on the other end. Parental acceptance reflects warmth, care, affection, support, and all other positive things that parents do for their children, while parental rejection reflects the opposite (Rohner \& Khaleque, 2005).

According to PARTheory, humans need to feel accepted by the people most important to them in childhood (Rohner, 1986). When people feel that their need for acceptance has not been met, they may develop a specific collection of dispositions that together define the acceptance-rejection syndrome (Rohner, 1999, 2004). The acceptance-rejection syndrome includes: 1) hostility and aggression; 2) dependence; 3) negative self-esteem; 4) negative self-adequacy; 5) emotional unresponsiveness; 6) emotional instability; 7) negative worldview; 8) anxiety; 9) insecurity; and 10) cognitive distortions (Rohner, 2004).

A multitude of cross-cultural studies have documented that perceived parental rejection is associated with the acceptancerejection syndrome among both children and adults, regardless of variations in race, culture, gender, language, and geographic region (Khaleque \& Rohner, 2002; Rohner \& Britner, 2002; Rohner \& Khaleque, 2010). Further, research has documented that perceived parental rejection and the acceptance-rejection syndrome are associated with a multitude of behavioral problems, including substance use (Campo \& Rohner, 1992; Rohner \& Britner, 2002).

\section{Motives to Drink Alcohol}

While researchers have documented that perceived parental rejection and the acceptance-rejection syndrome are associated with substance use (Campo \& Rohner, 1992; Rohner \& Britner, 2002), researchers have not documented if perceived parental rejection and the acceptance-rejection syndrome are associated with drinking motives, or self-perceived reasons for drinking alcohol. The concept of drinking motives is based on the assumption that people drink in order to attain valued outcomes (Cooper, 1994; Cox \& Klinger, 1988), whether those outcomes are related to the direct chemical effects of alcohol or to the indirect effects of alcohol, such as peer acceptance. A person does not have to be aware of either having made a decision to drink or the factors affecting this decision. In most cases, decisions about drinking are unconscious (Kuntsche, Knibbe, Gmel, \& Engels, 2005).

The literature on drinking motives suggests that, whether unconscious or conscious, there are distinct motives for drinking alcohol. According to Cooper, Russell, Skinner, and Windle (1992), there are three drinking motives. The first motive, coping, is aimed at reducing and/or avoiding negative emotional states. The second motive, sociability, is aimed at affiliating with others. The third motive, enhancement, is aimed at facilitating positive emotions.

\section{Drinking among Young Women}

Differences in gender account for variations in drinking habits, causes, and effects. For example, a woman is considered to be "binge drinking" when she consumes four or more alcoholic beverages on one occasion, while a man must consume at least five (Paul, Grubaugh, Frueh, Ellis, \& Egede, 2011). Women metabolize alcohol more slowly than men, which disallows 
them from drinking the same amount as men do without as many negative side effects (Wechsler, Dowdall, Davenport, \& Rimm, 1995).

Among the consequences women may experience due to drinking alcohol, sexual indiscretions are of particular concern. In addition to low inhibitions accounting for an increased likelihood of "consensual sex," intoxicated women may be at elevated risk for being victims of sexual assault. Larimer, Lydum, Anderson, and Turner (1999) found a correlation between women's excessive alcohol consumption and their sexual victimization. Even when sexual activity is not coercive per se, alcohol may play a role in women's partaking in risky sexual behavior. For example, in their study of African American women who drink alcohol, Seth, Wingood, DiClemente, and Robinson (2011) found that female drinkers were more likely than nondrinkers to have multiple sexual partners, to not use condoms with casual partners, and to have a sexually transmitted infection.

Despite seemingly convincing cause to refrain, women continue to drink alcohol, often heavily. In their study on the drinking motives of undergraduate women, Smith and Berger (2010) found a complex impetus for such behavior. First of all, college-age women drink as part of a "relational ritual" in which activities that surround drinking like parties and sporting events - and the subsequent "storytelling" from such activities - create new bonds with others and strengthen existing ones, two things women value highly. Second, the resulting cohesion of the group forms a kind of "protection" for them, securing them in the idea that they are part of a group. This protection softens the blow of any negative consequences that may result from drinking, including, but not limited to, academic limitations, physical danger, or the aforementioned sexual indiscretions, which are either not discussed or laughed off. As a result, a cycle is created in which high-risk drinking is promoted as a means of bonding, the bonding protects from negative consequences, and the lack of consequences promotes further drinking.

In addition to drinking alcohol for "relational rituals" and "protection," women may also drink to cope with low selfesteem. Research suggests that women with higher self-esteem have more proactive approaches to problem solving than those with lower self-esteem and are, therefore, less likely to drink alcohol as a way of coping (Boyd, Bland, Herman, Mestler, \& Murr, 2002).

\section{Purpose of the Present Study}

Although researchers have documented that perceived parental rejection and the acceptance-rejection syndrome are associated with substance use (Campo \& Rohner, 1992; Rohner $\&$ Britner, 2002), researchers have not documented if perceived parental rejection and the acceptance-rejection syndrome are associated with drinking motives, or self-perceived reasons for drinking alcohol. Therefore, the purpose of our study was to determine if, among young women specifically, perceived parental rejection is associated, via negative self-esteem, with the drinking motives identified by Cooper and colleagues (1992): coping, enhancement, and sociability. We chose negative selfesteem, one of the dispositions of the acceptance-rejection syndrome, because of its documented link with young women's alcohol use (Boyd et al., 2002).
We tested six indirect effects models. In Model One, we tested if higher levels of perceived maternal rejection would have an indirect effect, via more negative self-esteem, on coping motive (see Figure 1). In Model Two, we tested if higher levels of perceived paternal rejection had an indirect, via more negative self-esteem, on coping motive (see Figure 2). In Model Three, we tested if higher levels of perceived maternal rejection had an indirect effect, via more negative self-esteem, on enhancement motive (see Figure 3). In Model Four, we tested if higher levels of perceived paternal rejection had an indirect effect, via more negative self-esteem, on enhancement motive (see Figure 4). In Model Five, we tested if higher levels of perceived maternal rejection had an indirect effect, via more negative self-esteem, on sociability motive (see Figure 5). In Model Six, we tested if higher levels of perceived paternal rejection had an indirect effect, via more negative self-esteem, on sociability motive (see Figure 6). Due to the exploratory nature of our study, we did not make any a priori hypotheses.

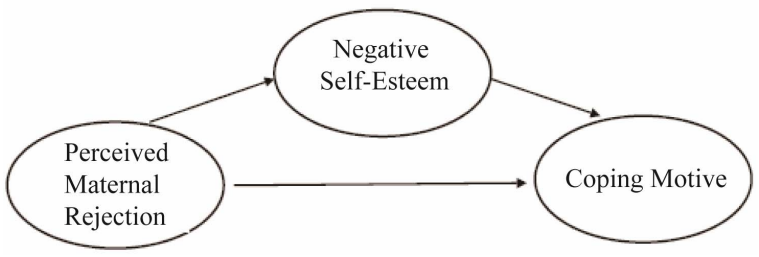

Figure 1.

Model one: proposed model for perceived maternal rejection and coping motive.

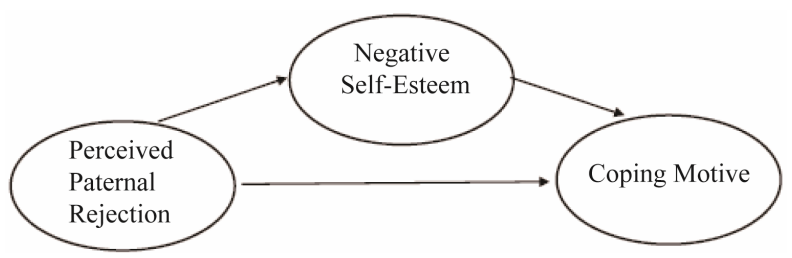

Figure 2.

Model two: proposed model for perceived paternal rejection and coping motive.

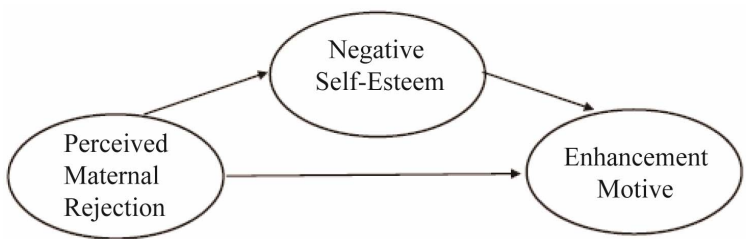

Figure 3.

Model Three: Proposed model for perceived maternal rejection and enhancement motive.

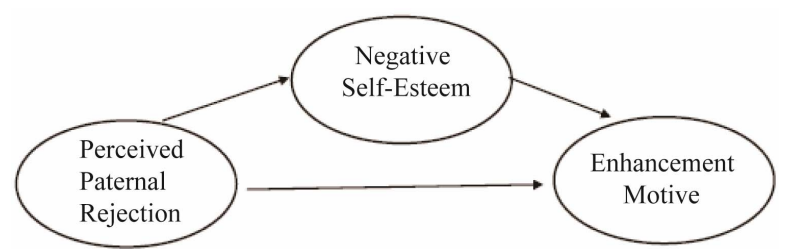

Figure 4.

Model four: proposed model for perceived paternal rejection and enhancement motive. 


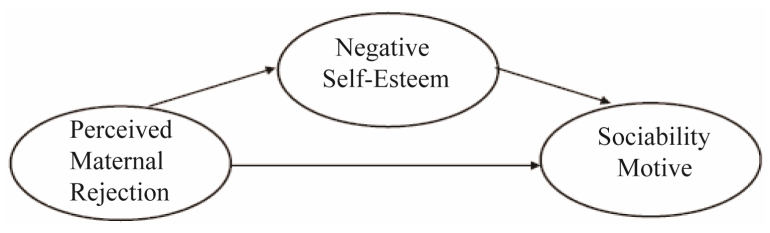

Figure 5.

Model five: proposed model for perceived maternal rejection and sociability motive.

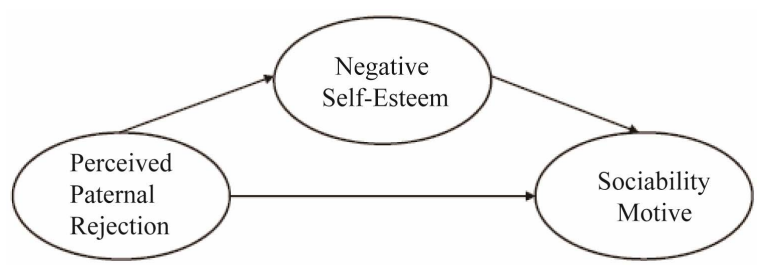

Figure 6.

Model six: proposed model for perceived paternal rejection and sociability motive.

\section{Method}

\section{Participants}

The participants were 95 female young adults $(M$ age $=21.15$ years, $S D=1.59$ ). The majority of the participants self-identified as Caucasian (88\%), with the remaining participants selfidentifying as Asian American (7\%), bi- or multi-racial (3\%), African American (1\%), and American Indian (1\%). One person chose not to respond.

\section{Materials}

Demographics. The participants completed a series of demographics that included age, ethnicity, and academic status (i.e., in school or not in school).

Perceived maternal rejection. The participants completed the Adult Parental Acceptance and Rejection Questionnaire: Mother (Short Form; Rohner \& Khaleque, 2005; $\alpha=.95$ ). This is a 24-item, 4-point, Likert-type self-report questionnaire designed to measure a person's perceptions of their mother's treatment of them during childhood. Sample items include: My mother ridiculed and made fun of me; My mother tried to make me feel better when I was hurt or sick. A higher cumulative score reflects a stronger perception of maternal rejection.

Perceived paternal rejection. The participants completed the Adult Parental Acceptance and Rejection Questionnaire: Father (Short Form; Rohner \& Khaleque, 2005; $\alpha=.95$ ). This measure is identical to the Adult Parental Acceptance and Rejection Questionnaire: Mother (Short Form; Rohner \& Khaleque, 2005) but it is answered with a person's father in mind. A higher cumulative score reflects a stronger perception of paternal rejection.

Negative self-esteem. The participants competed the Negative Self-Esteem subscale of the Personality Assessment Questionnaire (Rohner \& Khaleque, 2005; $\alpha=.88$ ). This subscale consists of nine items, rated on a 4-point scale, designed to measure how negatively a person feels about himself or herself. Sample items include: I certainly feel worthless; When I meet a stranger I think that s(he) is better than I am. A higher cumulative score reflects more negative self-esteem.

Drinking motives. The participants completed the Drinking
Motives Questionnaire (Cooper et al., 1992). This questionnaire consists of a total of 15 items rated on a 4-point scale, designed to measure three dimensions of a person's motives for alcohol use: 1 ) coping motive ( $\alpha=.84$; five items; e.g., How often do you drink because it helps you when you feel depressed or nervous?); 2) enhancement motive ( $\alpha=.82$; five items; e.g., How often do you drink because it is exciting?); and 3) sociability motive ( $\alpha=.70$; e.g., How often do you drink because it is customary on special occasions?). A higher mean score on each dimension reflects a stronger motive to drink.

\section{Procedure}

Before data collection began, approval was granted from the appropriate Institutional Review Board. The participants were recruited via snowball sampling on Facebook

(www.facebook.com). Potential participants were provided a link to a Web site that included the informed consent and questionnaire. If an individual chose to participate, she first read the informed consent and then completed the questionnaire. Participation in the study was anonymous.

\section{Results}

In order to test the six models, we analyzed each of them separately via indirect effects testing with bootstrapped resamples of 5000 (Preacher \& Hayes, 2008).

\section{Drinking Motive: Coping}

The results of Model One were significant $\left(p<.001, R^{2}=.16\right)$, with Bias Corrected Confidence Intervals of .0036 and .0232. Therefore, participants' perception of greater maternal rejection had an indirect effect (via more negative self-esteem) on their increased motivation for drinking alcohol as a way of coping.

The results of Model Two were also significant $(p=.001$, $R^{2}=.14$ ), with Bias Corrected Confidence Intervals of .0015 and .0138. Therefore, participants' perception of greater paternal rejection had an indirect effect (via more negative selfesteem) on their increased motivation for drinking alcohol as a way of coping.

\section{Drinking Motive: Enhancement}

The results of Model Three were non-significant $(p=.41$, $R^{2}=.02$, Bias Corrected Confidence Intervals $\left.=-.0056, .0134\right)$. The results of Model Four were also non-significant $(p=.47$, $R^{2}=.02$, Bias Corrected Confidence Intervals $\left.=-.0058, .0048\right)$. Therefore, neither perceived maternal rejection nor paternal rejection had an indirect effect (via more negative self-esteem) on participants' motivation for drinking alcohol as a way of enhancement.

\section{Drinking Motive: Social}

The results of Model Five were non-significant $(p=.75$, $R^{2}=.01$, Bias Corrected Confidence Intervals $\left.=-.0065, .0102\right)$. The results of Model Six were also non-significant $(p=.47$, $R^{2}=.02$, Bias Corrected Confidence Intervals $\left.=-.0058, .0048\right)$. Therefore, neither perceived maternal rejection nor paternal rejection had an indirect effect (via more negative self-esteem) on participants' motivation for drinking alcohol as a way of sociability. 


\section{Discussion}

The purpose of our study was to determine if, among young women specifically, perceived parental rejection is associated, via negative self-esteem, with the drinking motives identified by Cooper and colleagues (1992): coping, enhancement, and sociability. Our study included negative self-esteem, one of the dispositions of the acceptance-rejection syndrome, because of its documented link with young women's alcohol use (Boyd et al., 2002).

The results indicate that, among participants who perceived stronger maternal rejection, a stronger expression of negative self-esteem existed, which contributed to a stronger motivation for alcohol use as a coping method. The same held true for paternal rejection: Among participants who perceived stronger paternal rejection, a stronger expression of negative self-esteem existed, which contributed to a stronger motivation for alcohol use as a coping method. This suggests that young women may choose to drink alcohol, in part, as a way to cope with their low self-esteem, which could be an effect, in part, of having experienced maternal and/or paternal rejection.

Neither perceived maternal nor paternal rejection had an indirect effect on enhancement or sociability motives. The finding that perceived maternal and paternal rejection had an indirect effect on only the coping motive makes sense in light of PARTheory's coping subtheory. Although the least well-developed portion of PARTheory, the purpose of coping subtheory is to explore how some children and adults can cope with perceived rejection better than others (Rohner et al., 2011). The subtheory explains that there are affective copers, whose mental health remains relatively good despite their perceived rejection, and instrumental copers, who maintain success in task-oriented activities like work or school but have impaired emotional and mental health. From this, it is apparent that there are degrees of success in coping and, presumably, many paths by which to reach a state of coping, with some being healthier than others. This study provides evidence that one way in which people might cope with perceived parental rejection is via an unhealthy path of drinking alcohol.

The limitations to this study include a racially homogenous sample. Further, alcohol is a commonly used substance among young adults (Dawson, Grant, Stinson, \& Chou, 2004), perhaps making the results of this study less generalizable to older women. In addition, the present study is correlational, which precludes the ability to make any determinations of causality.

In the future, researchers might consider examining the role of perceived parental rejection in women's motivations to use substances other than alcohol. Further, researchers might also examine if additional dispositions of the parental acceptancerejection syndrome (e.g., negative worldview) connect young women's perceptions of parental rejection to their motivations for alcohol and other substance use. It is also important to note that although the $R^{2}$ values for Model One (.16) and Model Two (.14) were significant, there is still unexplained variance in the coping motive that was not accounted for by perceived maternal and paternal rejection, which invites an explanation from future research.

\section{REFERENCES}

Boyd, M. R., Bland, A., Herman, J., Mestler, L., Murr, L., \& Potts, L.
(2002). Stress and coping in rural women with alcohol and other drug disorders. Archives of Psychiatric Nursing, 16, 254-262. doi:10.1053/apnu.2002.37280

Campo, A., \& Rohner, R. P. (1992). Relationships between perceived parental acceptance-rejection, psychological adjustment, and substance abuse among young adults. Child Abuse and Neglect, 16, 429440. doi:10.1016/0145-2134(92)90052-S

Cooper, M. L., Russell, M., Skinner, J. B., \& Windle, M. (1992). Development and validation of a three-dimensional measure of drinking motives. Psychological Assessment, 4, 123-132. doi:10.1037/1040-3590.4.2.123

Cooper, M. L. (1994). Motivations for alcohol use among adolescents: Development and validation of a four-factor model. Psychological Assessment, 6, 117-128. doi:10.1037/1040-3590.6.2.117

Cox, W. M., \& Klinger, E. (1988). A motivational model of alcohol use. Journal of Abnormal Psychology, 97, 168-180. doi:10.1037/0021-843X.97.2.168

Dawson, D. A., Grant, B. F., Stinson, F. S., \& Chou, P. S. (2004). Another look at heavy episodic drinking and alcohol use disorders among college and noncollege youth. Journal of Studies on Alcohol and Drugs, 65, 477-488.

Khaleque, A., \& Rohner, R. P. (2002). Reliability of measures assessing the relation between perceived parental acceptance-rejection and psychological adjustment: A meta-analysis of cross-cultural and intracultural studies. Journal of Cross-Cultural Psychology, 33, 86-98. doi: $10.1177 / 0022022102033001006$

Kuntsche, E., Knibbe, R., Gmel, G., \& Engels, R. (2005). Why do young people drink? A review of drinking motives. Clinical Psychology Review, 25, 841-861. doi:10.1016/j.cpr.2005.06.002

Larimer, M. E., Lydum, A. R., Anderson, B. K., \& Turner, A. P. (1999). Male and female recipients of unwanted sexual contact in a college student sample: Prevalence rates, alcohol use, and depression symptoms. Sex Roles: A Journal of Research, 30, 3-4.

Paul, L. A., Grubaugh, A. L., Frueh, B. C., Ellis, C., \& Egede, L. E. (2011). Associations between binge and heavy drinking and health behaviors in a nationally representative sample. Journal of Addictive Behaviors, 36, 1240-1245. doi:10.1016/j.addbeh.2011.07.034

Preacher, K. J., \& Hayes, A. F. (2008). Asymptotic and resampling strategies for assessing and comparing indirect effects in multiple mediator models. Behavior Research Methods, 40, 879-891. doi:10.3758/BRM.40.3.879

Rohner, R. P. (1986). The warmth dimension: Foundations of parental acceptance-rejection theory. Beverly Hills, CA: Sage Publications, Inc.

Rohner, R. P. (1999). Acceptance and rejection. In D. Levinson, J. Ponzetti, \& P. Jorgensen (Eds.), Encyclopedia of human emotions (Vol. 1, pp. 6-14). New York: Macmillan Reference.

Rohner, R. P. (2004). The parental "acceptance-rejection syndrome": Universal correlates of perceived rejection. American Psychologist, 59, 830-840. doi:10.1037/0003-066X.59.8.830

Rohner, R. P., \& Britner, P. A. (2002). Worldwide mental health correlates of parental acceptance-rejection: Review of cross-cultural and intracultural evidence. Cross-Cultural Research, 36, 16-47. doi:10.1177/106939702129146316

Rohner, R. P., \& Khaleque, A. (2005). Handbook for the study of parental acceptance and rejection (4th ed.). Storrs, CT: Rohner Research Publications.

Rohner, R. P., \& Khaleque, A. (2010). Testing central postulates of parental acceptance-rejection theory (PARTheory): A meta-analysis of cross-cultural studies. Journal of Family Theory and Review, 3, 73-87. doi:10.1111/j.1756-2589.2010.00040.x

Rohner, R. P., Khaleque, A., \& Cournoyer, D. E. (2011). Introduction to parental acceptance-rejection theory, methods, evidence, and implications. URL (last checked 17 November 2011). www.cspar.uconn.edu

Seth, P., Wingood, G. M., DiClemente, R. J., \& Robinson, L. S. (2011) Alcohol use as a marker for risky sexual behaviors and biologically confirmed sexually transmitted infections among young adult African American women. Women's Health Issues, 2, 130-135. doi:10.1016/j.whi.2010.10.005

Smith, M. A., \& Berger, J. B. (2010). Women's ways of drinking: 


\section{RUNDELL ET AL.}

College women, high-risk alcohol use, and negative consequences. Journal of College Student Development, 51, 35-49. doi: $10.1353 /$ csd. 0.0107
Wechsler, H., Dowdall, G. W., Davenport, A., \& Rimm, E. B. (1995).

A gender-specific measure of binge-drinking among college students. American Journal of Public Health, 85, 982-985. 